\title{
Parental Belief dan Self-Esteem Anak: Studi pada Budaya Betawi
}

\author{
Sally Carolina \& Sri Hartati R. Suradijono
}

Fakultas Psikologi Universitas Indonesia

\begin{abstract}
Self-esteem is one aspect that can affect the mental development of children and will further affect the well-being of individuals. One of the factors that can influence is parenting from parents. Parental belief is one of the factors that play a role to underlie the behavior of parents to children. This study aims to see the picture of the dimensions that on parental belief variable, that is child rearing of belief scale, attribute of intelligence, and educational goals, as well as its influence on the development of selfesteem in elementary school-age children, especially in grade 3, 4 and 5 elementary school children on the people of the Betawi culture. Betawi culture is used as a special context in this study because it has unique characteristics when compared to other cultures in Indonesia. The number of participants included in this study were 36 participants spread across several areas of Jakarta. The parental belief in Betawi culture according to the dimensions in $P B Q$ is obtained in the dimensions of the child rearing belief scale, the highest subdimension is developing practical skills; on the dimensions of attributes of intelligence, the highest subdimension is motivation for school tasks; and on the dimensions of the educational goals, the highest subdimension is emphasize conformity. To see the effect of dimensions on parental belief in self esteem, researchers use multiple regression methods. The results obtained there were no significant effects of each dimension of parental belief in children self-esteem..
\end{abstract}

Keywords: Betawi culture, parental beliefs, parenting, self-esteem

\section{Pendahuluan}

Penelitian mengenai pola asuh

Sally Carolina dan Sri Hartati R. Suradijono berasal dari Fakultas Psikologi Universitas Indonesia. Korespondensi artikel ini dialamatkan ke Sally Carolina, dengan alamat e-mail: salli_carolina@yahoo.com orang tua telah banyak dilakukan di

berbagai negara. Sebagian besar penelitian

tersebut membahas mengenai seperti apa

pola asuh orang tua terhadap anaknya,

apakah pola asuh autoritatif, autoritarian, 
dan permisif. Apabila ditelusuri lebih lanjut, orang tua dari latar belakang budaya yang berbeda, baik dari satu negara ataupun berbeda negara, akan memiliki pandangan atau gagasan yang bervariasi mengenai pola asuh dan perkembangan anak (Goodnow, 1988; Goodnow \& Collins, 1991; Miller, 1988; Bornstein, 1991). Bentuk gagasan/kepercayaan ini biasa disebut dengan parental beliefs.

\section{Parental Beliefs}

Menurut Matsumoto dan Juang (2013), parental beliefs adalah suatu bentuk kepercayaan yang dimiliki orang tua yang dapat mempengaruhi perilaku orang tua dalam mengasuh anak yang terlihat dalam hubungan interaksi antara orang tua dan anak sehari-harinya. Pengetahuan yang menjadi kepercayaan orang tua, secara sadar atau tidak sadar akan ditampilkan melalui komunikasi ataupun interaksi langsung dengan harapan anak mereka dapat mempelajari secara observasi dan imitasi. Kepercayaan orang tua akan meningkat melalui pengalaman sehari-hari dan diinternalisasi dalam diri kemudian digabungkan dengan kepercayaan yang dimiliki sebelumnya (Doménech \& Selva, 2015).

Faktor utama yang mempengaruhi perilaku dalam mengasuh anak adalah spesifik belief yang dimiliki orang tua, pikiran (kognisi), dan perasaan yang teraktivasi saat mengasuh anak. Faktor kognisi dapat terkait dengan belief yang dimiliki orang tua mengenai kemampuan dalam mengasuh anak, harapan mengenai apa yang anak dapat lakukan dan apa yang seharusnya dilakukan, dan alasan mengapa anak berperilaku tertentu (Miller, 1988). 
Menurut Matsumoto dan Juang (2013), belief adalah sesuatu yang dianggap benar, dan setiap individu pada budaya yang berbeda akan memiliki belief yang berbeda pula, dan dapat meningkat melalui pengalaman. Pengalaman memerlukan belief yang dimiliki sebelumnya dan alasan mengapa pengalaman itu diasimilasi dan alasan mengapa pengalaman perlu dibentuk, sama halnya dengan belief membutuhkan penalaran. Belief, penalaran, dan pengalaman adalah tergantung satu sama lain (Doménech \& Selva, 2015).

Hasil dari parental beliefs dalam pola asuh anak akan mempengaruhi perkembangan anak salah satunya pada perkembangan kognitif anak, yang pada akhirnya akan mempengaruhi kemampuan anak dalam pencapaian di sekolahnya. Oleh karena itu, tidak jarang juga dilakukan penelitian yang berkaitan dengan pola asuh orang tua dan pencapaian akademik anak di sekolah (academic achievement). Okagaki dan Sternberg (1993), mengemukakan bahwa perbedaan dalam parental beliefs mengenai pemeliharaan anak banyak dipengaruhi oleh perbedaan pendidikan yang dimiliki oleh orang tua daripada nilai budaya yang dimiliki secara umum. Beberapa literatur secara konsisten mengatakan bahwa pendidikan orang tua merupakan faktor penting dalam memprediksi pencapaian yang didapatkan anak (Klebanov, Brooks-Gunn, \& Duncan, 1994; Haveman \& Wolfe, 1995 \& Smith, Brooks-Gunn, 1997).

Pembentukan parental beliefs erat kaitannya dengan kemampuan critical thinking yang dimiliki orang tua serta modifikasinya (Huit, 1998). Salah satu faktor yang dapat mempengaruhi adalah pengalaman orang tua. Pengalaman 
terdahulu saat orang tua masih anak-anak telah terekam dalam ingatan orang tua yang kemudian dijadikan pedoman dalam kesehariannya termasuk dalam mengasuh anak. Akan tetapi, seiring waktu dengan adanya proses belajar, belief tersebut akan mengalami penyesuaian dengan konteks lingkungan sehingga akan membentuk parental beliefs yang baru (Huit, 1998). Parental beliefs juga tidak lepas dari pengaruh budaya termasuk budaya teknologi. Kemudahan dalam mengakses informasi melalui media sosial ataupun acara-acara TV menyebabkan budaya dari luar pun dapat masuk dengan mudah dan mempengaruhi individu dalam kesehariannya (Grusec \& Danyliuk, 2014).

Indonesia sebagai salah satu negara yang memiliki beragam suku bangsa, memiliki variasi dalam nilai, tradisi, dan adat istiadat. Oleh karena itu, dapat dikatakan parental beliefs yang dimiliki tentu saja akan sangat bervariasi. Salah satu budaya yang menjadi perhatian penulis adalah budaya Betawi. Menurut sejarahnya, orang Betawi merupakan satu suku bangsa yang timbul sebagai hasil asimilasi dari berbagai suku bangsa yang melalui proses yang panjang. Pandangan mengenai awal mula terbentuknya budaya Betawi menyebutkan bahwa budaya ini merupakan keturunan Bangsa Asia kelas rendah yang banyak terdapat di Batavia. Orang Betawi lahir dari kawin campur berbagai keturunan, termasuk Cina, Bali, Sunda, serta suku lainnya, dan kemudian terbentuknya identitas atau suku tersendiri (Suswandari, 2017).

Ajaran Islam dijadikan identitas utama pada etnik Betawi dan menjadi pembeda dengan kelompok lain di Jakarta (Farlina, 2012). Ajaran yang diberikan dalam Islam tidak hanya mempengaruhi 
nilai-nilai sebagai pedoman dalam kehidupan sehari-hari, tetapi juga menjadi pola solidaritas sebagai identitas khas Betawi. Selain itu, orang Betawi dikenal sebagai suku yang memiliki sikap toleransi yang tinggi, terlihat pada sikap keramahtamahan. Proses pengambilan keputusan dilakukan secara asas mufakat (Suswandari, 2017).

Beberapa ciri orang Betawi di anataranya adalah cenderung membentuk kelompok tersendiri, sangat dekat dengan ajaran agama Islam, dalam bidang pekerjaan lebih condong pada perdagangan, pendidikan lebih kepada pesantren, menganut sistem patrilineal, sulit menerima ide baru, dan suka tolongmenolong (Ya'la, 2000).

Karakteristik-karakteristik yang dijelaskan di atas menjadi alasan penulis dalam memilih budaya Betawi sebagai latar belakang partisipan. Penulis juga ingin mengetahui, apakah sejauh mana budaya yang dimiliki pada orang Betawi ini akan mempengaruhi parental belief yang dimiliki para orang tua.

\section{Self-Esteem}

Self-esteem dapat diartikan sebagai evaluasi positif atau negatif yang dimiliki seseorang mengenai dirinya sendiri (Rosenberg, Schooler, Schoenbach, \& Rosenberg, 1995). Sementara itu, Neff (2011) mendeskripsikan self-esteem sebagai evaluasi penghargaan diri sebagai seseorang, suatu penilaian terhadap diri sendiri bahwa diri kita merupakan seorang yang berharga.

Komponen-komponen dari selfesteem menurut Felker (1974) terdiri dari perasaan diterima (feeling of belonging), perasaan mampu (feeling of competence), dan perasaan berharga (feeling of worth). 
Pendapat ini juga didukung oleh berbagai definisi dari para teoris lainnya, salah satunya oleh Harter yang mengatakan bahwa self-esteem berkaitan dengan penilaian diri (self-worth), bagaimana individu menilai dirinya. Akan tetapi tidak hanya mengenai penilaian diri tetapi juga mengenai kompetensi diri (Harter, 1999).

Setiap tindakan yang dilakukan dalam bekerja ataupun di sekolah, baik pada orang dewasa ataupun anak-anak selalu dipengaruhi bagaimana mereka memandang diri mereka. Hal ini terlihat dari berbagai penelitian yang terkait level self-esteem. Sebagai contoh Brown (2010) menemukan bahwa self-esteem berbanding lurus dengan resiliensi yang dimiliki oleh individu. Jika dikaitkan dengan self-esteem, dikatakan bahwa selfesteem yang tinggi akan menghasilkan nilai relasional yang tinggi, sementara selfesteem rendah akan menghasilkan nilai relasional yang rendah dan meningkatkan kemungkinan adanya penolakan ditolak (Baldwin \& Sinclair, 1996). Individu yang memiliki self-esteem yang tinggi juga akan memotivasi individu untuk mencapai tujuan yang positif. Sementara itu, individu dengan self-esteem rendah akan berbanding lurus dengan evaluasi diri, juga menghasilkan kurangnya kejelasan diri, dan kepercayaan diri (Blaine \& Crocker, 1993; Leary \& Baumeister, 2000). Individu dengan self-esteem rendah umumnya akan lebih menggunakan langkah menghindar jika menemukan suatu masalah (Murray et al., 2002), serta lebih memilih untuk menghindari perasaan inferior untuk mengatasi dirinya apabila menghadapi kemungkinan adanya penolakan atau kehilangan harga diri (Sommer, Williams, Ciarocco, \& Baumeister, 2001). 
Menurut Murk (2006), beberapa penelitian menyebutkan salah satu faktor utama yang dapat memengaruhi perkembangan self-esteem pada anak adalah orang tua. Sebagaimana yang dikemukakan oleh Bronfenbrenner dalam teori ekologi, perkembangan anak akan sangat dipengaruhi oleh lingkungan mikrosistemnya, yaitu lingkungan yang secara langsung berinteraksi dengan anak, yaitu keluarga, di mana di dalamnya terdapat orang tua (Bronfenbrenner, 1994). Orang tua akan mempengaruhi anaknya melalui pola asuh yang diberikan, di mana setiap perilaku pola asuh yang dilakukan orang tua awalnya adalah berupa ide, kepercayaan, dan berdasarkan pengalamannya sendiri.

Berdasarkan penjelasan di atas, peneliti ingin melihat pengaruh parental beliefs terhadap self-esteem anak, dilihat berdasarkan dimensi yang diukur dalam
Parental Beliefs Questionnairre (PBQ) yaitu child-rearing beliefs, attributes of intelligence, dan educational objectives. Hal ini menurut peneliti perlu untuk diteliti, melihat bahwa self-esteem sangat berpengaruh dalam keseharian anak, termasuk dalam pencapaian akademiknya di sekolah. Kebaruan dari penelitian ini bila dibandingkan dengan penelitian lainnya adalah memaparkan dan penggunaan budaya Betawi sebagai konteks khusus. Selain itu, penilaian selfesteem pada anak usia sekolah dasar masih sangat jarang.

Pertanyaan penelitian berdasarkan penjelasan yang dipaparkan adalah bagaimana pengaruh parental beliefs orang tua dengan suku bangsa Betawi dilihat dari child-rearing beliefs, attributes of intelligence, dan educational objectives terhadap self-esteem anak. 
Hipotesis penelitian yang diajukan adalah adanya pengaruh yang signifikan dari parental beliefs orang tua dengan suku bangsa Betawi dilihat dari childrearing beliefs, attributes of intelligence, dan educational objectives terhadap selfesteem anak.

\section{Metode Penelitian}

\section{Partisipan Penelitian}

Target awal jumlah partisipan dalam penelitian ini adalah 50 partisipan, yang terdiri dari orang tua dan anak yang sedang berada di sekolah dasar, khususnya kelas 3, 4, dan 5 SD. Peneliti menetapkan jumlah partisipan berdasarkan sejumlah referensi yang menyebutkan minima jumlah partisipan 1 yang dapat dianalisis secara regresi. Akan tetapi, pada akhir pelaksanaan, jumlah partisipan berkurang menjadi 36 partisipan. Hal ini dikarenakan, 14 orang tua lainnya bukanlah orang Betawi murni.

Peneliti memilih budaya Betawi sebagai konteks budaya dikarenakan berdasarkan literatur yang ada dan hasil wawancara, budaya ini, memiliki ciri khas tertentu yaitu dari pembentukan budaya itu sendiri, yaitu merupakan hasil akulturasi dari banyak budaya yang terkumpul di Batavia, dari luar Indonesia ataupun dari dalam Indonesia (Suswandari, 2017). Dengan demikian, peneliti ingin melihat gambaran dari budaya tersebut dilihat dari dimensi yang ada pada PBQ.

Usia anak yang dipilih oleh partisipan adalah usia sekolah kelas 3, 4, dan 5 SD. Periode ini berada pada tahap middle childhood, di mana menurut teori perkembangan psikososial, anak berada pada tahap industry vs inferiority. Pada tahap ini, anak sedang membangun hubungannya dengan lingkungan sosial 
dan kompetensinya. Saat anak dapat mencapai tujuan yang diharakannya, maka kepercayaan dirinya akan bertambah, tetapi jika tidak, anak akan merasa inferior (Feist, Feist, \& Robert, 2013). Hal ini dapat mempengaruhi perkembangan selfesteemnya (Erikson, 1968). Selain itu, jugda dikatakan bahwa perkembangan psikologi anak usia middle childhood akan mempengaruhi perkembangan psikologi positif pada masa dewasa nantinya (Erikson, 1968).

Teknik sampling yang digunakan dalam penelitian ini adalah purposive sampling, karena peneliti menetapkan beberapa kriteria dalam pemilian sampel agar dapat menjawab pertanyaan serta tujuan dari penelitian.

\section{Instrumen Penelitian}

Alat ukur yang dipakai untuk mengukur parental beliefs adalah Parental Beliefs
Questionnaire (PBQ) (Okagaki \& Sternberg, 1993). Alat ukur ini terdiri dari tiga dimensi yang berhubungan dengan parental beliefs mengenai pola asuh anak (child-rearing beliefs), inteligensi (attributes of intelligence), dan tujuan pendidikan (education objectives). Masing-masing dari dimensi tersebut terdiri atas beberapa subdimensi. Skala yang dipakai dalam alat ukur ini adalah skala Likert (tidak penting, sedikit penting, agak penting, cukup penting, sangat penting, sangat penting sekali). Sebelum digunakan, alat ukur PBQ telah melalui proses penerjemahan dan adaptasi terlebih dahulu. Nilai reliabilitas dari PBQ adalah child-rearing beliefs 0,811, attributes of intelligence 0,934, dan educational objectives 0,950 .

Alat ukur yang dipakai untuk mengukur self-esteem adalah Rosenberg Self-Esteem Scale (Rosenberg, 1965), 
yang bersifat unidimensional. Pilihan jawaban menggunakan skala Likert yaitu sangat setuju, setuju, tidak setuju, dan sangat tidak setuju. Nilai reliabilitas dari RSES adalah 0,673.

\section{Desain Penelitian}

Penelitian ini merupakan penelitian kuantitatif dan termasuk jenis penelitian eksploratory research. Oleh karena tidak dilakukan eksperimen, maka juga dapat disebut penelitian noneksperimen.

\section{Prosedur Penelitian}

Sebelum dilakukan pengambilan data, peneliti mengajukan permohonan kaji etik dari institusi. Setelah mendapatkan persetujuan kaji etik, peneliti melakukan pengambilan data di wilayah yang dianggap terdapat keluarga dengan budaya Betawi.

Penulis melakukan penelitian di beberapa wilayah, yaitu wilayah Tebet, Cinere, Krukut, dan Beji. Untuk pengumpulan data, penulis menggunakan kuesioner dan wawancara singkat dengan partisipan (orang tua dan anak). Selain menggunakan alat ukur yang dipilih, penulis juga menyusun pertanyaanpertanyaan secara lisan mengenai budaya Betawi dengan tujuan agar penulis juga memiliki gambaran tentang budaya Betawi.

\section{Analisis Data}

Teknik analisis data yang peneliti gunakan dalam penelitian ini adalah teknik analisis regresi berganda (multiple regression). Pemilihan teknik ini karena dimensi pada parental beliefs tidak dapat menggunakan skor total 
karena setiap dimensi memiliki konsep yang berbeda dari setiap dimensi. Program yang digunakan adalah SPSS 22.0

Dalam pengolahan data, peneliti menggunakan nilai mean dari setiap dimensi yang ada lalu dianalisis secara analisis regresi berganda secara bersamaan. Sebelum dilakukan analisis regresi, data yang didapatkan telah dilakukan uji normalitas dan uji multikolineliaritas, di mana pada uji normalitas didapatkan data berdistribusi normal, dan pada uji multikolinearitas didapatkan bahwa tidak terdapat gejala multikolinearitas.

\section{Hasil dan Pembahasan}

Setiap dimensi pada PBQ ini memiliki beberapa subdimensi, yaitu developing problem solving, developing creative skills, developing conforming

behavior, dan developing practical skills.

Tabel 1 Nilai Mean Dimensi Child Rearing Beliefs

\begin{tabular}{lc}
\hline \multicolumn{1}{c}{$\begin{array}{c}\text { Subdimensi Child } \\
\text { Rearing Beliefs }\end{array}$} & $\begin{array}{c}\text { Nilai Mean } \\
\text { Kepentingan }\end{array}$ \\
\hline Problem Solving & 5.206 \\
Creative & 4.778 \\
Conform & 5.257 \\
Practical & 5.215
\end{tabular}

(Probem-Solving: developing problem solving; Creative: developing creative skill; Conform: developing conformity behavior; Practical: developing practical skill)

Jika dilihat pada Tabel 1, nilai yang terendah dari keempat subdimensi tersebut adalah subdimensi developing creative skills (4.778). Hal ini berarti ratarata menurut orang tua mengembangkan kemampuan kreativitas anak memiliki derajat kepentingan yang terendah bila dibanding dengan subdimensi lainnya. Sementara itu, aspek yang tertinggi adalah subdimensi developing conforming behavior (5.257), yang berarti menurut orang tua bersuku bangsa Betawi, 
mengembangkan perilaku conforming merupakan aspek terpenting dalam merawat anak.

Dimensi kedua dalam PBQ adalah attributes of intelligence. Subdimensi yang terdapat pada dimensi ini adalah importance of problem-solving skills, importance of verbal skills, importance of creative skills, importance of social skills, importance self-management skills, dan importance of motivation for school task. Berdasarkan perhitungan didapatkan, subdimensi importance of motivation for school task memiliki nilai tertinggi, yaitu sebesar (5.573). Hal ini berarti menurut orang tua pentingnya motivasi terhadap tugas-tugas sekolah merupakan aspek yang paling utama dalam karakteristik intelegensi.
Tabel 2 Nilai Mean Subdimensi Attributes of Intelligence

\begin{tabular}{lc}
\hline $\begin{array}{c}\text { Subdimensi Attributes of } \\
\text { Intelligences }\end{array}$ & $\begin{array}{c}\text { Nilai Mean } \\
\text { Kepentingan }\end{array}$ \\
\hline Prob-Solve & 4.906 \\
Verbal & 5.278 \\
Creative & 5.217 \\
Social & 5.266 \\
Self-Manage & 5.544 \\
Motivation for School Task & 5.573 \\
(Prob-Solve: importance of problem-solving \\
skills; Verbal: importance of verbal skills; \\
Creative: importance of creative skills; Social: \\
importance of social skills; Self-Manage: \\
importance of self-management skills; \\
Motivation for School Task: importance of \\
motivation for school task)
\end{tabular}

Dimensi ketiga dalam PBQ adalah educational objectives. Subdimensi dalam dimensi ini adalah cognitive abilities, academic conformity, emphasize conformity, dan developing independence.

Tabel 3 Nilai Mean Subdimensi Educational Objectives

\begin{tabular}{lc}
\hline \multicolumn{1}{c}{$\begin{array}{c}\text { Subdimensi } \\
\text { Education Objectives }\end{array}$} & $\begin{array}{c}\text { Nilai Mean } \\
\text { Kepentingan }\end{array}$ \\
\hline Cog-Abilities & 5.454 \\
Conf-Presentation & 5.500 \\
Emph-Conf & 5.681 \\
Dev-Ind & 5.375 \\
\hline \multicolumn{2}{c}{$($ Cog-Abilities: cognitive abilities; } \\
Conf-Presentation: conformity in presentation of \\
work; Emph-Conf: emphasize conformity; Dev- \\
Ind: development independence)
\end{tabular}


Pada Tabel 3 dapat dilihat nilai tertinggi diperoleh pada aspek emphasize conformity, yaitu sebesar 5.681. Hal ini berarti menurut kepercayaan orang tua Betawi, aspek dalam mengajarkan anak terkait penekanan conformity memiliki kepentingan yang tertinggi.

Pada gambaran variabel selfesteem didapatkan nilai minimal dari partisipan adalah 26, sedangkan nilai maksimum adalah 37. Sementara, nilai rata-rata self-esteem yang diperoleh adalah 30.44, dengan $\mathrm{SD}=2.71$.

Setelah itu, dilakukan analisis regresi berganda antara parental beliefs terhadap self-esteem. Hasil yang didapatkan adalah $\mathrm{R}=0,262 ; \mathrm{R}^{2}=0,069$; $\mathrm{SE}=0,27345 ; \mathrm{F}=0,785 ;$ dan $\mathrm{Sig} .=0,511$. Berdasarkan hasil ini, dapat dikatakan tidak adanya pengaruh yang signifikan pada parental beliefs terhadap selfesteem $(\mathrm{p}>0,05)$.

\section{Diskusi}

Berdasarkan hasil yang didapatkan, parental beliefs pada suku Betawi menilai perilaku conforming memiliki derajat kepentingan lebih tinggi daripada mengembangkan otonomi dalam pola asuh terhadap anaknya. Hal ini dapat terlihat pada nilai developing conforming behavior pada dimensi childrearing beliefs dan emphasize conformity pada dimensi educational objectives. Hal ini sejalan dengan karakteristik dari orang Betawi yang dikemukakan oleh Suswandari (2017) yaitu orang Betawi memiliki pola solidaritas dan toleransi tinggi yang terlihat pada sikap keramahtamahannya. Bahkan dalam pengambilan keputusan, orang Betawi lebih kepada asas mufakat. Selain itu, orang Betawi juga sangat taat pada ajaran Agama Islam, dan melestarikan kebudayaan yang berkaitan hingga saat ini. 
Hal ini juga dapat dikaitkan dengan budaya Betawi yang sangat menghormati orang tua dalam keluarga mereka, serta kentalnya ajaran agama Islam yang ditanamkan oleh orang tua kepada anak-anaknya. Nilai-nilai yang terdapat pada budaya Betawi sangat erat kaitannya dengan agama Islam, demikian eratnya sehingga dapat dikatakan Islam sebagai identitas utama yang dimiliki Betawi (Suwandari, 2017).

Ide mengenai intelegensi yang dinilai pada dimensi attributes of intelligence terlihat bahwa orang tua bersuku bangsa Betawi menganggap bahwa pentingnya motivasi terhadap tugas sekolah merupakan hal yang paling penting untuk menggambarkan konsep intelegensi bila dibandingkan dengan aspek lainnya.

Berdasarkan wawancara dengan beberapa partisipan, pada awalnya, kepentingan dalam pendidikan menurut orang tua bersuku Betawi jaman dahulu, tidaklah terlalu tinggi. Orang tua hanya mengharapkan anak mereka sekadar bisa membaca, berhitung, dan menulis. Jika dilihat dari tingkat pendidikan, dapat dilihat orang tua Betawi mayoritas pendidikan yang dimiliki hanyalah sampai batas sekolah menegah atas. Akan tetapi, dengan bertambah sulitnya persaingan, orang tua mulai berpikir bahwa pendidikan merupakan hal yang penting agar dapat berhasil nantinya. Hal ini dapat dilihat dari nilai motivation for school task mendapatkan nilai tertingggi (5.573) dalam dimensi attributes of intelligence.

Analisis regresi berganda yang dilakukan pada parental beliefs terhadap self-esteem ternyata didapatkan hasil yang tidak signifikan $(p=0.511)$. Dengan kata lain, tidak ditemukan adanya pengaruh yang signifikan pada parental beliefs terhadap self-esteem. Analisis 
yang dilakukan ini adalah hasil analisis yang dilakukan secara bersamaan antara setiap dimensi yang ada pada parental beliefs. Menurut peneliti, ada kemungkinan akibat adanya pengaruh antar-dimensi dapat mempengaruhi signikansi. Jika dilihat berdasarkan teori, faktor yang mempengaruhi self-esteem salah satunya adalah pola asuh (childrearing) (Mruk, 2006) di mana hal ini berdekatan dengan dimensi childrearing beliefs. Sementara itu, untuk dimensi attributes of intelligence dan educational objectives lebih terkait pada kemampuan sosial dan akademik. Selain itu, hasil yang didapatkan juga dapat berarti kemungkinan terdapat faktor lain yang dapat mempengaruhi perkembangan self-esteem anak pada partisipan penelitian ini.

Seperti yang dikatakan oleh Mruk (2006) faktor yang dapat mempengaruhi self-esteem selain pola asuh adalah gender dan lingkungan. Terlebih lagi, usia partisipan yaitu anak usia sekolah dasar, di mana menurut Erikson berada pada tahap industry vs inferiority. Pada tahap ini, anak mulai membina hubungan dengan lingkungannya, misalnya sekolah atau teman bermainnya serta membangun citra dirinya sebagai seorang yang memiliki kemampuan (skills). Jika anak dapat melaksanakan tugas dan menghasilkan sesuatu yang baik, anak akan memiliki rasa industry yang baik, sebaliknya jika tidak, anak akan merasa inferior (Feist, Feist, \& Roberts, 2013). Dengan kata lain, aspek lainnya yang dapat berpengaruh adalah kompetensi yang dimiliki oleh anak (Harter, 1999). Selain itu, pada masa ini anak belajar untuk mengerjakan dan menghasilkan sesuatu dengan baik. Jika anak merasa lebih banyak merasa bersalah, dan terlalu sedikit tujuan saat usia bermain, mereka 
akan merasa inferior dan tidak kompeten selama usia sekolah, hingga akhirnya dapat mempengaruhi self-esteem-nya (Feist, Feist, \& Roberts, 2013).

Penjelasan ini menunjukkan adanya kemungkinan dari variabel lain yang dapat mempengaruhi self-esteem selain parental beliefs atau kemungkinan perlu adanya variabel lain yang menjadi moderator ataupun mediator untuk memperkuat pengaruh dari parentalbeliefs terhadap self-esteem anak. Oleh karena itu, untuk penelitian selanjutnya dapat diteliti variabel lainnya yang dapat mempengaruhi self-esteem anak dalam konteks budaya Betawi.

Penelitian ini merupakan preliminary research yang dilakukan penulis sebelum melanjutkan penelitian berikutnya yang berkaitan dengan parental beliefs. Beberapa kekurangan dari penelitian ini salah satunya adalah jumlah partisipan yang masih kurang dan wilayah yang masih belum mencakup keseluruhan wilayah yang dianggap sebagai kampung Betawi. Oleh karena itu, peneliti menyarankan pada penelitian berikutnya dapat dilakukan penelitian yang memiliki partisipan yang lebih banyak dan mencakup wilayah yang lebih luas, serta latar belakang budaya yang lebih bervariasi. Selain itu, disarankan pada penelitian berikutnya terkait budaya, ada baiknya mengadaptasi bahasa yang ada pada alat ukur disesuaikan dengan budaya yang akan dijadikan konteks tertentu agar sesuai dengan tujuan yang ingin dicapai.

Peneliti berharap dengan adanya penelitian ini dapat memberikan informasi terkait dengan topik selfesteem dan parental beliefs serta kaitannya dengan budaya. Melalui penelitian ini juga dapat tergambar nilai rata-rata dari self-esteem anak usia middle childhood. 


\section{Daftar Pustaka}

Baldwin, M. W., \& Sinclair, L. (1996). Self-esteem and the "if . . then" contingencies of interpersonal acceptance. Journal of Personality and Social Psychology, 71, $1130-$ 1141.

Blaine, B., \& Crocker, J. (1993). Selfesteem and self-serving biases in reactions to positive and negative events: An integrative review. In R. F. Baumeister (Ed.), Plenum series in social/clinical psychology. Selfesteem: The puzzle of low selfregard (pp. 55-85). New York, NY, US: $\quad$ Plenum $\quad$ Press. http://dx.doi.org/10.1007/ 978-14684-8956-9_4.

Bornstein, M. H. (1991). Approaches to parenting in culture. Cultural approaches to parenting, 3-19.

Bronfenbrenner, U. (1994). Ecological models of human development. International Encyclopedia of
Education. Vol 3. $2^{\text {nd }}$ ed. Oxford: Elsevier.

Brown, J.D. (2010). High self-esteem buffers negative feedback: Once more with feeling, Cognition and Emotion, 24:8, 1389-1404,

DOI: $10.1080 / 026999309035$

04405.

Doménech, J.L.U \& Selva, J.N. (2015). What are belief system? Springer Science Bussiness Media Dordrecht, 2015. Departement of Applied Mathematics, University of Alicante. Spain.

Erikson, E. (1968). H.(1968). Identity: Youth and crisis.

Farlina, N. (2012). "Represenetasi identitas Betawi”. Thesis. Tidak diterbitkan. Fakultas Ilmu Budaya Universitas Indonesia.

Feist J., Feist. G. J., \& Roberts, T. (2013). Theories of Personality. $8^{\text {th }}$ Ed. New York: McGraw-Hill Education. 
Felker. (1974). The Development of Self Esteem. New York: William Morrow \& Company.

Goodnow, J. J. (1988). Parents' ideas, actions, and feelings: Models and methods from developmental and social psychology. Child Development, 59, 286 - 320.

Goodnow, J. J. (1996). From household practices to parent's idea about work and interpersonal relationships. In S. Harkness, \& C. M. Super (Eds.). Parents' cultural belief systems: Their origins, expressions, and consequences (pp. 333 - 357). New York: The Guilford Press

Goodnow, J. J. (2002). Parents' knowledge and expectations: Using what we know. In M. H. Bornstein (Ed.), Handbook of parenting: Being and becoming a parent (pp. 439-460). Mahwah, NJ, US: Lawrence Erlbaum Associates Publishers.

Goodnow, J.J., \& Collins, A.W. (1991). Development according to parents: The nature, sources, and consequences of parents ideas. Hilsdale, NJ: Erlbaum.

Grusec, J.E. \& Danyliuk, T. (2014). Parents' attitudes and beliefs: their impact on children's development, Parenting Skill. Encyclopedia on Early Childhood Development. Canada

Harter, S. (1999). Distinguished contributions in psychology. The construction of the self: A developmental perspective. New York: Guilford Press.

Haveman, R., \& Wolfe, B. (1995). The determinants of children's attainments: A review of methods and findings. Journal of Economic Literature, 33, $1829-1878$.

Huit, W. (1998). Critical thinking: An overview. Educational Psychology Interactive. Valdosta, GA: Valdosta State University.

Klebanov, P. K., Brooks-Gunn, J., \& Duncan, G. J. (1994). Does 
neighborhood and family poverty affect mothers' parenting, mental health, and social support? Journal of Marriage and the Family, 56, $441-455$

Leary, M. R., \& Baumeister, R. F. (2000). The nature and function of self-esteem: Sociometer theory. In M. P. Zanna (Ed.), Advances in experimental social psychology, Vol. 32, pp. 1-62). San Diego, CA, US: Academic Press. http://dx.doi.org/10.1016/

Matsumoto, D. \& Juang, L. (2013). Culture and Psychology. $5^{\text {th }}$ ed. USA: Wadsworth, Cengage Learning.

Miller, S. A. (1988). Parents' beliefs about children's cognitive development. Child development, 259-285.

Miller, S. A. (1988). Parents' beliefs about children's cognitive development. Child development, 259-285.

Mruk, C. J. (2006). Self-esteem research, theory and practice toward a positive psychology of self-esteem. New York: Sringer Publising Company.

Murray, S. L., Rose, P., Bellavia, G. M., Holmes, J. G., \& Kusche, A. G. (2002). When rejection stings: How self-esteem constrains relationshipenhancement processes. Journal of Personality and Social Psychology, $83,556-573$

Neff, K. D. (2011). "Self-compassion, self-esteem, and wellbeing." Social and Personality Psychological Compass, 5, 1-12. doi:10.1111/ j.1751-9004.2010.00330.x.

Okagaki, L. \& Sternberg, R.J. (1993). Parental belief and children's school performance. Child Development, 64, 36-56. Yale University 
Rosenberg, M. (1965). Society and the Adolescent Self-image. Princeton, NJ: Princeton University Press.

Rosenberg, M., Schooler, C., Schoenbach, C., \& Rosenberg, F. (1995). Global self-esteem and specific self-esteem: Different concepts, different outcomes. American sociological review, 141-156. S0065-

2601(00)80003-9.

Smith, J. R., Brooks-Gunn, J., \& Klebanov, P. K. (1997). Consequences of living in poverty for young children's cognitive and verbal ability and early school achievement. In G. J. Duncan \& J. Brooks-Gunn (Eds.), Consequences of growing up poor (pp. 132-189). New York: Russell Sage Foundation.
Sommer, K. L., Williams, K. D., Ciarocco, N. J., \& Baumeister, R. F. (2001). When silence speaks louder than words: Explorations into the intrapsychic and interpersonal consequences of social ostracism. Basic and Applied Social Psychology, 23(4), 225-243.

Suswandari. (2017). Kearifan local etnik Betawi: Mapping sosio-kultural masyarakat asli Jakarta. Yogyakarta: Pustaka Pelajar.

\section{Ya'la, A. (2000). "Perubahan sosial} komunitas Betawi: studi kasus di Kelurahan Kembangan Selatan, Kecamatan Kembangan, Jakarta Barat." Thesis. Tidak diterbitkan. Universitas Indonesia. 